\title{
NUMERICAL MODELLING AND POWER TAKE OFF CHARACTERIZATION OF A WAVE ENERGY CONVERTER WITH BOUNDARY ELEMENT METHOD
}

\author{
Mario López ${ }^{1}$, Paulo Rosa-Santos ${ }^{2}$ and Francisco Taveira-Pinto ${ }^{2}$
}

\begin{abstract}
This paper deals with the numerical modelling of an innovative technology for harnessing wave energy and its power take-off system. The investigated wave energy converter is CECO, a device based on the principles of oscillating bodies that is being developed at the Faculty of Engineering of the University of Porto, Portugal. The particularity of this concept lies on the relative motion between a floating part and a supporting one, which is restricted to translations along an inclined direction. First, the wave energy converter is modelled in the frequency domain by means of a panel model that is based on the boundary element method. Once obtained the frequency-dependent hydrodynamic coefficients of the floating part, the dynamic equation of motion is solved in the time domain by including, not only the hydrodynamic forces, but also the force of the power take-off system. The results prove the ability of the numerical modelling approach to simulate the behavior of the device and provide insight into its performance.
\end{abstract}

Keywords: WEC; oscillating body; numerical model; panel model, Aqwa, capture width.

\section{INTRODUCTION}

Harnessing the unexploited wave energy resource is of major research interest, as it can contribute substantially to increase the share of renewables and reduce the fossil fuels dependence of many countries worldwide (López et al., 2015). Over the past decades, many wave energy converters (WECs) have been proposed and investigated; nonetheless, the production cost of wave energy cannot compete yet with the traditional energy sources (Taveira-Pinto et al. 2015).

One of the major drawbacks in the design of an efficient technology is the harshness of the marine environment (Muliawan et al. 2013). In addition, the wave energy resource variability in different time and space scales also adds complexity to the problem (Carballo et al. 2015). Given that the efficiency of a WEC strongly depends on the wave climate at the site for exploitation (Veigas et al. 2014, and 2015), a vast number of test conditions should be considered during the different testing stages.

The latter makes it indispensable to apply both physical and numerical modelling during the development of any WEC (Ruehl and Bull 2012). Whilst experimental laboratory tests allow the conversion procedure to be evaluated under controlled and precise wave conditions, the numerical modelling allows the design of a WEC to be optimized at a lower cost (López et al. 2014).

Among the numerical methods applied to simulate the performance of a WEC, the most common are those based on the Reynolds Averaged Navier-Stokes (RANS) equations and those based on the potential flow theory, which are solved with the Boundary Element Method (BEM). The application of RANS models has been restricted mostly to $2 \mathrm{D}$ analyses of fixed WECs because of the high computational cost of this type of models (Zhang et al. 2012). On the contrary, the models based on potential flow theory are usually suitable for most of the cases - and especially for 3D analyses of floating WECs (Day et al 2015).

The BEM-based models, so-called panel models, were developed decades ago to assess the hydrodynamic performance of ships and ocean platforms. Currently, these models are being applied with success to simulate the behavior of different typologies of WEC. For instance, Delaure and Lewis (2003) and Bosma et al. (2014) analyzed different configurations of oscillating water columns, Rhinefrank et al. (2011) applied the method to investigate point absorbers, and Payne et al. (2008) characterized the behavior of a new free-floating sloped device.

In this work, the numerical modelling of the CECO concept is presented. This WEC is based on the principles of oscillating bodies, in which the relative motion of a floating element to a fixed structure is used to harness wave energy (Rosa-Santos et al. 2015). As a difference with other oscillating bodies, CECO has the motions of its floating part restricted to an inclined direction (Fig. 1), which results in a higher efficiency to capture the wave energy (López et al. 2016).

The numerical modelling methodology applied in this work includes the use of the BEM to obtain the hydrodynamic coefficients of large volume elements. Subsequently, the dynamic equation of the device is solved in the time domain to obtain the motion time series. The non-linear Froude-Krylov forces, the hydrostatic forces and the Morison forces are calculated at each time step for the elements beneath the incident waves. In addition, the instantaneous power take-off (PTO) force is represented in

\footnotetext{
${ }^{1}$ Department of Construction and Manufacturing Engineering, University of Oviedo, EPM C/ Gonzalo Gutierrez Quiros s/n, Mieres, Asturias, 33600, Spain

2 Interdisciplinary Centre of Marine and Environmental Research (CIIMAR) and Department of Civil Engineering, Faculty of Engineering, University of Porto, Rua Dr. Roberto Frias s/n, Porto, 4200 - 465, Portugal
} 
the model by adding two terms to the dynamic equation of the device. To achieve this, two empirical parameters are calibrated with the results from previous experimental tests conducted at the wave basin of the Hydraulics, Water Resources and Environment Division of the Faculty of Engineering of the University of Porto (Portugal). The complete numerical procedure is implemented in Ansys ${ }^{\circledR}$ Aqwa ${ }^{\mathrm{TM}}$, a widely used numerical tool for the study and design of marine structures (Ansys 2016).

The remainder of the paper is structured as follows: Section 2 presents a more detailed description of CECO along with the material and methods used in this investigation, with a special focus on the numerical model used. Section 3 shows the results of the calibration and the validation of the numerical model and presents the efficiency of CECO for different wave conditions. Finally, the main conclusions and implications of the work are drawn in Section 4.
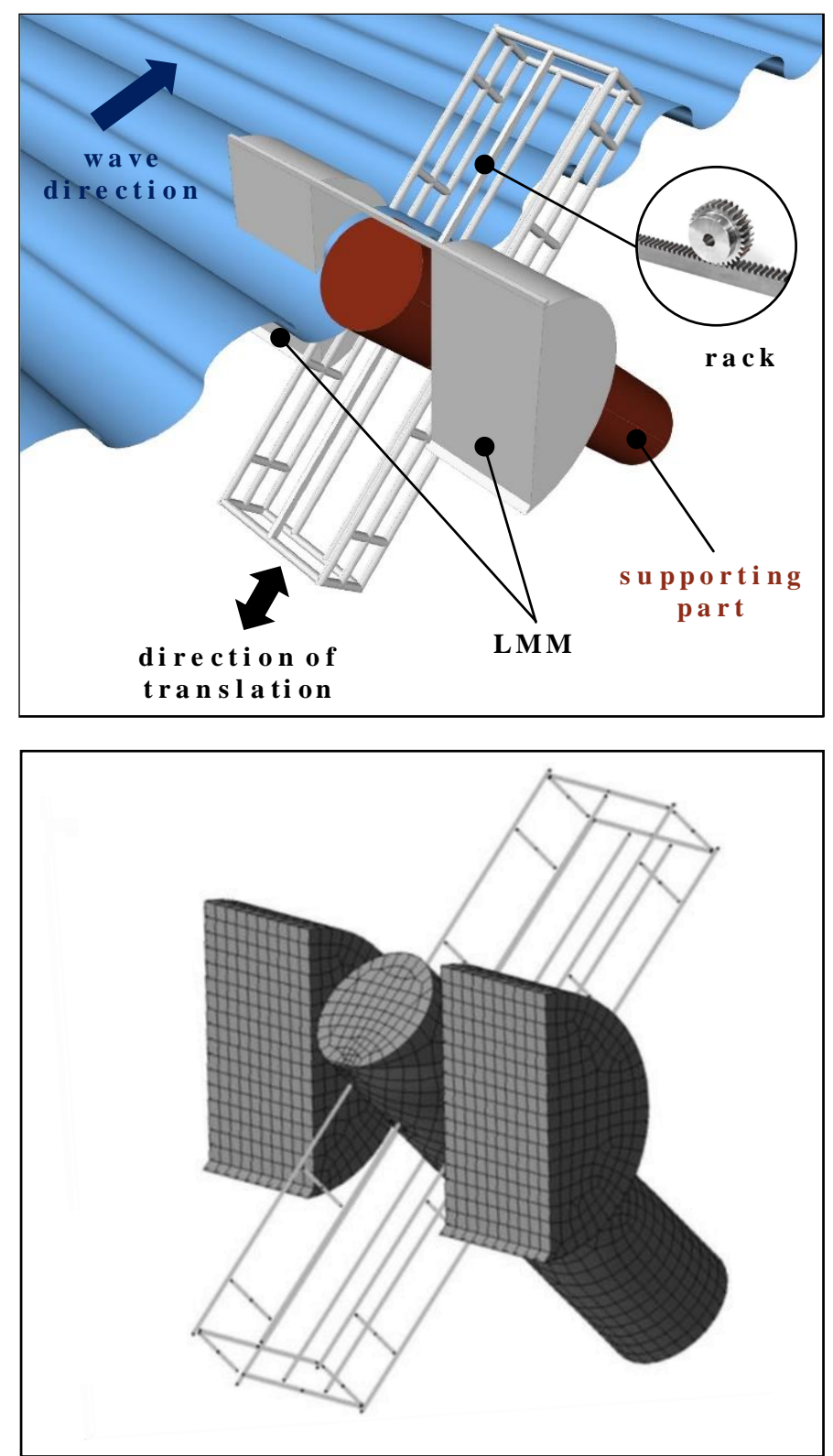

Figure 1. A sketch of CECO (upper panel) and the mesh used in the numerical model (lower panel).

\section{MATERIAL AND METHODS}

\subsection{The CECO model}

CECO has two well differentiable parts: an oscillating and a supporting one (Fig. 1). The former is composed of two floating lateral mobile modules (LMM) linked by a frame made of tubular elements 
and has its movements restricted to one degree of freedom (DOF) that corresponds to an inclined translation. The second one consists of an inclined cylinder that provides support to the moving assembly and is thought to house an electric generator and auxiliary systems. A description of the different conversion stages is presented in the following.

The ocean waves excite the CECO moving part; i.e., the incoming waves transfer part of their energy to the two semi-submerged LMM. A portion of the total captured energy is returned to the ocean in the form of radiated waves and the rest of the energy is converted into mechanical energy. While the moving part of CECO oscillates in an oblique direction, the mechanical energy is simultaneously transmitted and transformed into usable energy by the PTO system. A rack-pinion system (which is composed of a rack linked to a central rod and a gear located inside the fixed part) converts translations into rotations and, finally, a generator connected to the gear converts the mechanical energy into electrical energy.

By considering the wave energy conversion process, the dynamic equation of the CECO floating part can be expressed as

$$
m \ddot{\xi}=f_{e}+f_{D}+f_{r}+f_{s t}+f_{\text {PTO }}
$$

where $m$ is the total mass of the moving elements; $\xi$ is the motion of CECO along its inclined direction of translation; $f_{e}$ is the wave excitation force, which includes the Froude-Krylov forces, the diffraction forces and the wave inertia forces; $f_{D}$ is the drag force; $f_{r}$ is the radiation force; $f_{s t}$ is the hydrostatic restoring force; and $f_{P T O}$ is the force associated to the PTO system, expressed in a linearized form as

$$
f_{\text {PTO }}=F+C \dot{\xi}
$$

where $F$ is a constant force and $C$ is a damping coefficient. The effects of the electric generator where not included; therefore, the term $f_{P T O}$ only accounts for the mechanical losses in the energy conversation machinery.

CECO is scalable and configurable. For instance, the LMMs can take different forms, sizes and/or submersion levels and the direction of motion of the floating part can be changed while the front face of the LMM remains vertical. The dimensions of CECO considered in this work are summarized in

\begin{tabular}{|c|c|c|}
\hline Property/dimension & Value & Units \\
\hline Height of the LMM & 8.00 & $\mathrm{~m}$ \\
\hline Width of the LMM & 4.50 & $\mathrm{~m}$ \\
\hline Total width or beam & 14.68 & $\mathrm{~m}$ \\
\hline Freeboard of the LMM & 3.38 & $\mathrm{~m}$ \\
\hline Total volume of the LMM submerged & 60.00 & $\%$ \\
\hline Mass of the floating part & 146.40 & $\mathrm{t}$ \\
\hline Working water depth & 16.00 & $\mathrm{~m}$ \\
\hline Direction of translation to an horizontal plan & 45.00 & deg \\
\hline
\end{tabular}
Table 1.

\subsection{Parameters}

To study the response of CECO to waves, both regular and irregular wave conditions were considered. Regular waves were characterized by their wave period $(T)$ and wave height $(H)$. Irregular wave conditions were defined by means of the peak wave period $\left(T_{p}\right)$ and the significant wave height $\left(H_{s}\right)$, assuming a JONSWAP power spectrum model $\left(S_{J}\right)$.

The wave energy flux per unit crest length $(J)$ of regular waves was obtained with,

$$
J=\frac{1}{8} \rho g H^{2} c_{g}
$$

where $\rho$ is the sea water density, $g$ is the acceleration of gravity and $c_{g}$ is the wave group celerity, while the energy flux per unit crest length of irregular waves as obtained with,

$$
J=\rho g \int_{0}^{\infty} S_{J}(\omega) c_{g}(\omega) d \omega
$$

The average captured wave energy during a test or a simulation $(P)$ was calculated as, 


$$
P=\overline{f_{e} \cdot \dot{\xi}},
$$

while the efficiency of the device was characterized by means of the capture width $\left(C_{W}\right)$ and the relative capture width $\left(C_{N}\right)$. The former is defined as the ratio of the average captured wave power to the wave energy flux per unit crest length,

$$
C_{W}=\frac{P}{J}
$$

The second parameter considers the dimensions of the device, and is equal to the capture width divided by to the overall width of the device $(B)$, which was considered equal to $14.68 \mathrm{~m}$ in this work (Table 1 ),

$$
C_{N}=\frac{C_{W}}{B} .
$$

\subsection{Numerical model approach}

A hybrid approach was used to perform the numerical modelling of CECO. On the one hand, the contours of the LMM and the central element (i.e., the large volume elements) were modelled as diffracting elements. These elements where discretized with triangular and quadrilateral panels with a maximum size of $80 \mathrm{~cm}$ (prototype scale) as shown in Figure 1. On the other hand, the frame, the rack and the rods (i.e., the small cross sectional elements) were modelled as Morison elements.

The 3-dimensional Boundary Element Method (BEM), so called panel method, was used to obtain the frequency-dependent hydrodynamic coefficients of the diffracting elements. The BEM is based on the fluid potential flow theory, and is widely used to solve the interaction of waves with ships and or marine structures (Bosma et al. 2014).

The method stablishes a linear system to solve the velocity potential at a point with coordinates $(X, Y, Z)$ due to incident, diffracted and radiated waves,

$$
\varphi(X, Y, Z) e^{-i \omega t}=\left[\varphi_{I}+\varphi_{d}+\sum_{j=1}^{6} \varphi_{r j} x_{j}\right] e^{-i \omega t}
$$

where $\varphi_{I}$ is the first order incident wave potential with unit wave amplitude, $\varphi_{d}$ is the corresponding diffracted wave potential, $\varphi_{r j}$ is the radiated wave potential due to the $j$-th motion with unit motion amplitude, and $x_{j}$ is the motion amplitude of the $j$-th DOF excited by an incident regular wave with unit amplitude. The velocity potentials are solved with a boundary integration approach and satisfying the following six boundary conditions:

Laplace equation,

$$
\frac{\partial^{2} \varphi}{\partial X^{2}}+\frac{\partial^{2} \varphi}{\partial Y^{2}}+\frac{\partial^{2} \varphi}{\partial Z^{2}}=0,
$$

applicable everywhere in the fluid domain.

Linear free surface equation of zero forward speed case,

$$
-\omega^{2} \varphi+g \frac{\partial \varphi}{\partial z}=0
$$

The body boundary conditions on the mean wetted body surface $\left(S_{0}\right)$,

$$
\frac{\partial \varphi_{d}}{\partial n}=\frac{-\partial \varphi_{I}}{\partial n}
$$

and

$$
\frac{\partial \varphi_{r, j}}{\partial n}=-i \omega n_{j}
$$

where $n_{j}$ is the $j$-th component of the unit normal vector of the body surface pointing outwards.

A seabed surface condition, 


$$
\frac{\partial \varphi}{\partial z}=0
$$

The far-field boundary condition (i.e., for which the generalized wave disturbance dies away),

$$
\varphi_{d}=\varphi_{r, j}=0 \text {. }
$$

Once solved the potentials, the hydrodynamic coefficients corresponding to the diffracting parts namely, the diffraction force coefficient $\left(F_{d}\right)$, the added mass matrix $(A)$, and the hydrodynamic damping matrix $(B)$ - were obtained and stored in a hydrodynamic database. The $j$-th diffracting force due to diffraction of waves can be obtained as:

$$
F_{d, j}(\omega)=-i \omega \rho \int_{S_{0}} \varphi_{d} n_{j} d S
$$

while the added mass and damping matrices are given by,

$$
\begin{aligned}
& A_{j k}(\omega)=\frac{\rho}{\omega} \int_{S_{0}} \operatorname{Im}\left(\varphi_{r k}\right) n_{j} d S \\
& B_{j k}(\omega)=-\rho \int_{S_{0}} \operatorname{Re}\left(\varphi_{r k}\right) n_{j} d S
\end{aligned}
$$

with $j, k=(1, \ldots, 6)$.

The position time series of the moving part, with a time step of $\Delta t=0.1 \mathrm{~s}$ (model scale) was obtained by solving the equation of motion (Eq. 1). The diffraction force on the panel elements was obtained as a linear superposition of the force due to each wave frequency component,

$$
f_{d}(t)=\sum_{m=1}^{N} a_{m} \operatorname{Re}\left[e^{i \omega_{m} t} e^{i \varepsilon_{m}} F_{d}\left(\omega_{m}\right)\right]
$$

where $N$ is the number of wave components, $a_{m}$ is the wave amplitude of the $\mathrm{m}$-th wave component, and $\varepsilon_{m}$ is the wave phase of the $m$-th component. The non-linear Froude-Krylov and the hydrostatic forces $f_{s t}$ were calculated at each time step on all elements beneath the incident waves (including both diffracting panels and tube elements). The wave inertia forces on the tube elements, as well as the drag forces $f_{D}$, were calculated with the Morison equation. The radiation force, $f_{r}$, was obtained based on the Cummins (1962) formulation as,

$$
f_{r}=-A_{\infty} \ddot{x}-\int_{0}^{t} h(t-\tau) \dot{x}(\tau) d \tau
$$

where $A_{\infty}$ is the fluid added mass matrix when frequency tends to infinity, and the acceleration impulse function matrix that represents the fluid memory effects is defined by,

$$
h(t)=\frac{2}{\pi} \int_{0}^{\infty} B(\omega) \frac{\sin (\omega t)}{\omega} d \omega=\frac{2}{\pi} \int_{0}^{\infty}\left\{A(\omega)-A_{\infty}\right\} \cos (\omega t) d \omega
$$

The forces associated to the PTO system, $f_{\text {PTO }}$, were calculated with Eq. 2.

The instant values of all these forces were applied to the moving part of CECO via a set of nonlinear equations of motion and the resulting accelerations were determined. Finally, the position and velocity at each time step were determined integrating the accelerations with a two-stage predictorcorrector numerical integration scheme. To implement this time-domain approach, the tool Aqwa Naut was used (ANSYS, 2016).

\subsection{Experimental tests}

The data from previous physical modelling tests were used to calibrate and validate the numerical model and, particularly, the empirical coefficients in Eq. 2. The tests were conducted in a wave basin at the Hydraulics Laboratory of the Hydraulics, Water Resources and Environment Division, of the Faculty of Engineering of the University of Porto (Fig. 2). The wave basin, which has the following dimensions $28.0 \times 12.0 \times 1.2 \mathrm{~m}^{3}$, is equipped with a multi-element piston-type wave maker with an active 
wave absorption system to reduce wave reflection. The water surface elevation was measured with resistive wave gauges and the CECO movements in the 6-DOF were recorded with a motion capture system composed of two digital infrared cameras.

A physical model of a CECO unit with the prototype dimensions described in Table 1 was built on a geometrical scale of 1:20. Bearings were used to properly guide the rods through the central element and to minimize the mechanical losses during the wave energy conversion process. In addition, a heavy and stable base was used to hold the fixed part in position and to avoid fluctuations that could interfere in the dynamics of the device.

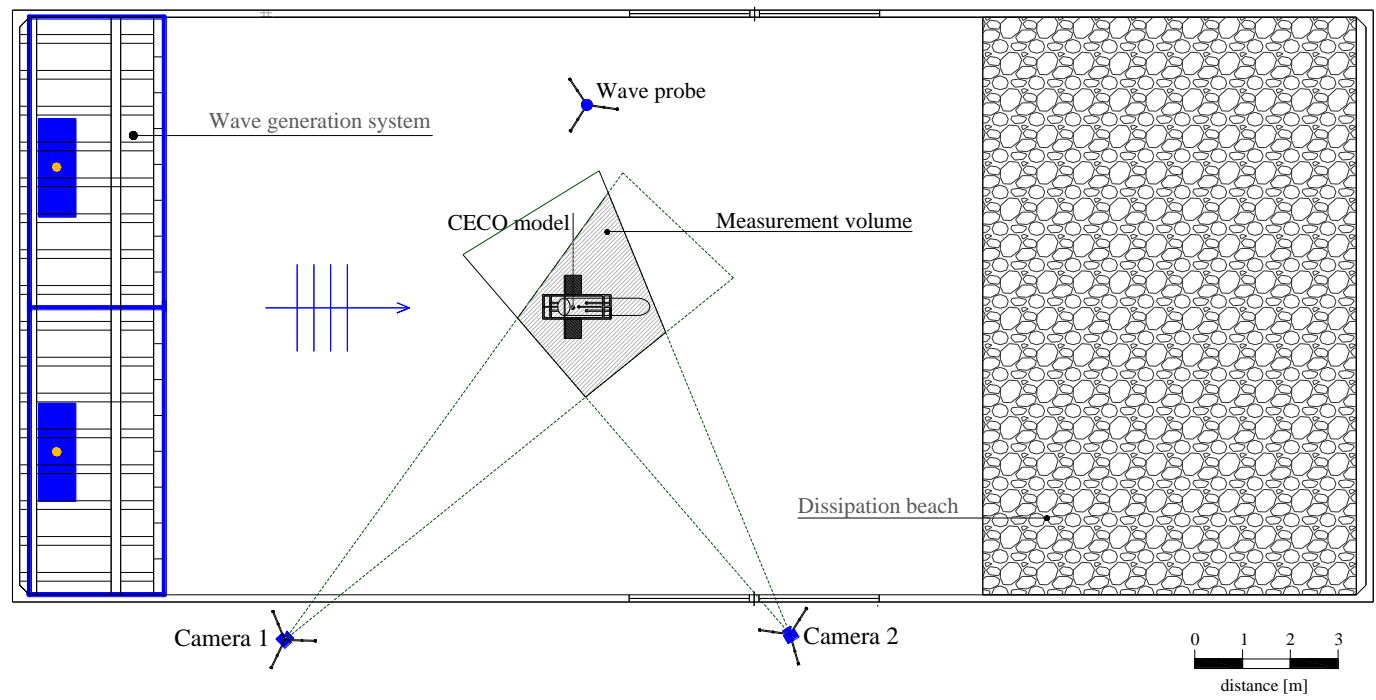

Figure 2. Experimental set-up used to the test CECO at the wave basin of the Faculty of Engineering of the University of Porto (Portugal).

\section{RESULTS}

\subsection{Numerical model calibration}

The parameters $F$ and $C$ (Eq. 2), which depend on the mechanical losses in the PTO conversion machinery, were calibrated with the results from the experimental tests. With this aim, the regular wave conditions reproduced during the experimental tests were simulated with the numerical model. Table 2 summarizes the wave conditions corresponding to each test case.

Each test case was simulated with 78 different pairs of values for $F$ and $K$, which resulted in a total of 390 simulations. For each simulation, the time series of CECO motions $(\xi)$ obtained with the numerical model were compared with the experimental counterpart. The correlation coefficient $(R)$ and the average value of the normalized root mean square error $(e)$ were used to quantify the agreement between the numerical and the physical approaches.

The pair of values that minimized the error between the numerical and the physical model results was $F=24 \mathrm{kN}$ and $C=53 \mathrm{kN} . \mathrm{s} . \mathrm{m}^{-1}$. As can be observed in Figure 3, the time series obtained in the numerical model with the latter values agree very well for all the wave conditions tested $(R>95 \%$ and $e<12 \%$ for all cases).

\begin{tabular}{|c|c|c|c|}
\hline \multicolumn{2}{|c|}{ Regular waves } & \multicolumn{2}{|c|}{ Irregular waves } \\
\hline$H[\mathrm{~m}]$ & $T[\mathrm{~s}]$ & $H_{s}[\mathrm{~m}]$ & $T_{p}[\mathrm{~s}]$ \\
\hline 1 & 8 & 1 & 8 \\
\hline 2 & 8 & 2 & 8 \\
\hline 2 & 10 & 2 & 10 \\
\hline 2 & 12 & 2 & 12 \\
\hline 3 & 10 & & \\
\hline 3 & 12 & & \\
\hline
\end{tabular}



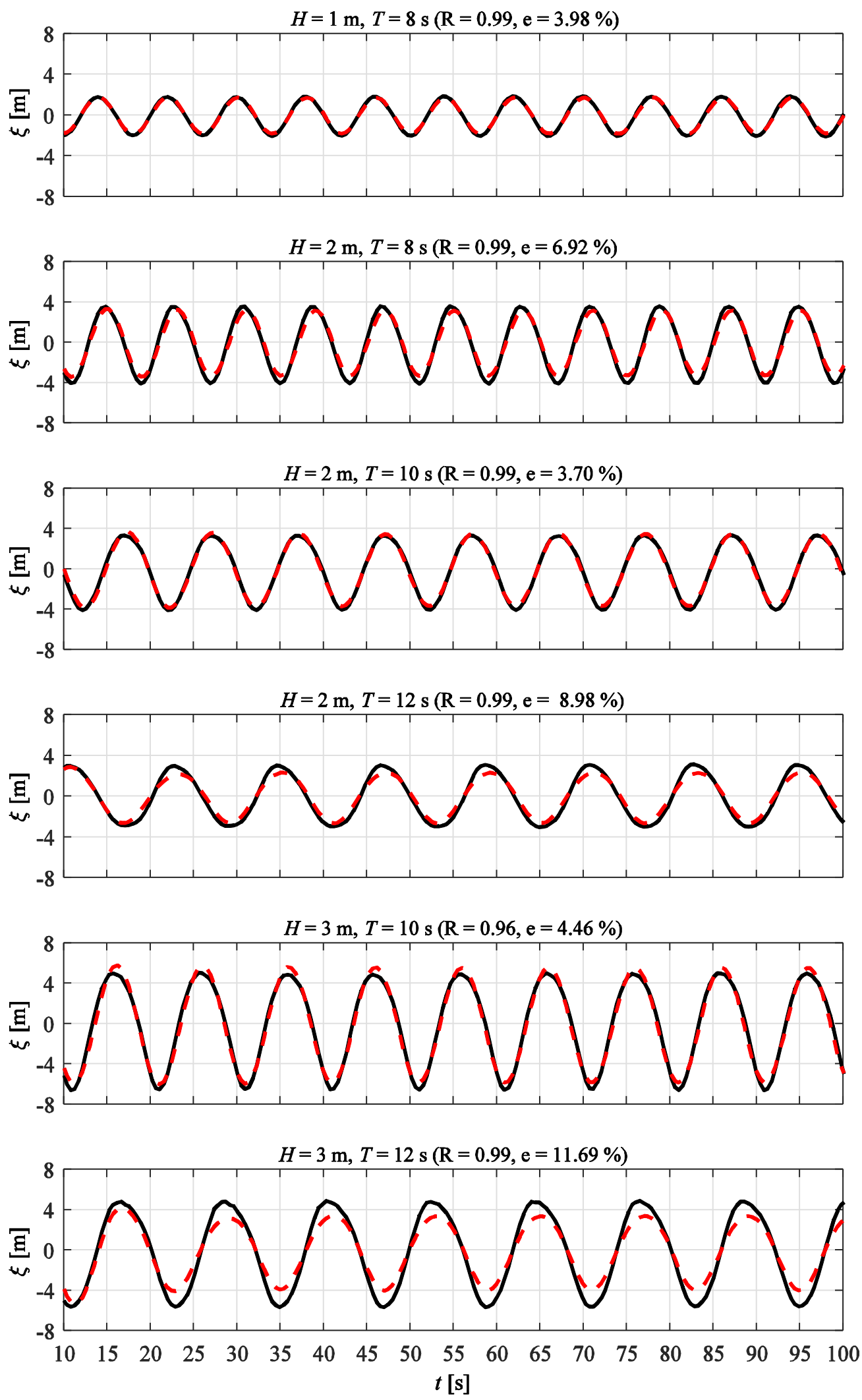

Figure 3. The CECO motion time series for different regular wave conditions. The continuous black lines correspond to the physical model results and the discontinuous red lines to the numerical model results. 


\subsection{Numerical model validation}

Additional simulations with irregular waves were carried out to check the ability of the model to reproduce more realistic conditions. The power density spectra of the CECO motions was calculated for each simulation. Figure 4 compares the spectra obtained from the numerical model results and the one resulting from the experimental data. As can be observed, the main peaks are properly reproduced - i.e., where most of the energy is concentrated and, thus, the frequency range of greatest interest. Considering the good agreement with the physical model results, the numerical model was considered appropriate and calibrated.
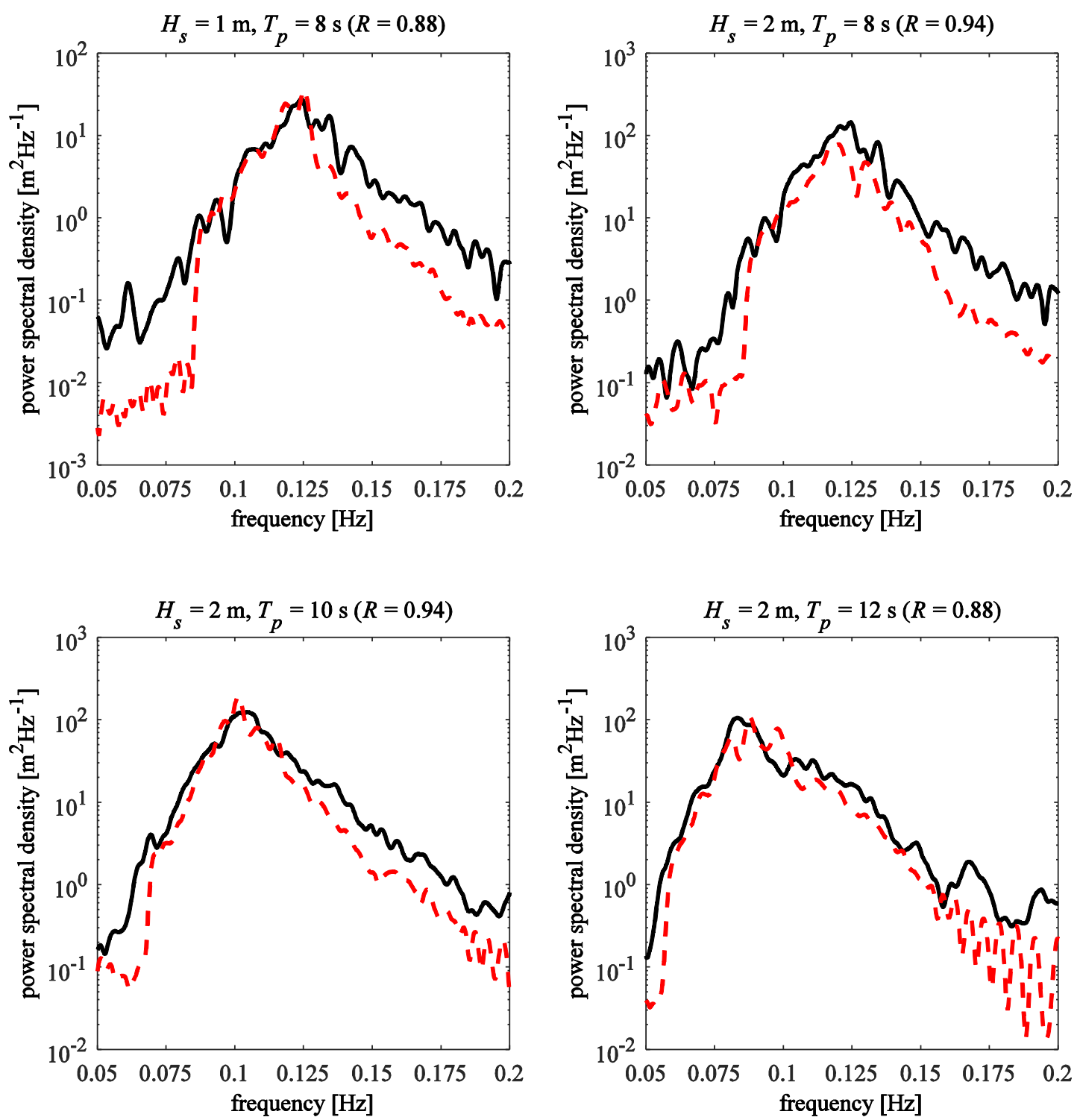

Figure 4. The motion spectra of CECO for the different irregular wave conditions. The continuous black lines correspond to the physical model results and the discontinuous red line to the numerical model results.

\subsection{Response amplitude operators}

To investigate the performance of CECO, an additional set of numerical model tests was carried out under regular wave conditions, corresponding to $H=0.5,1.0,2.0,3.0$ and $4.0 \mathrm{~m}$ and $T=7,8,9,10$ 11 and $12 \mathrm{~s}$. The response amplitude curves were then obtained for each test (Fig. 5). In the vicinity of the curves' peak (i.e., around $T=9$ or $10 \mathrm{~s}$ ), the motion response amplitude of the device is four times the wave counterpart. On the basis of these results, the ability of CECO concept to amplify the motion amplitude of its oscillating part with respect to the amplitude of the incident waves is proved. 


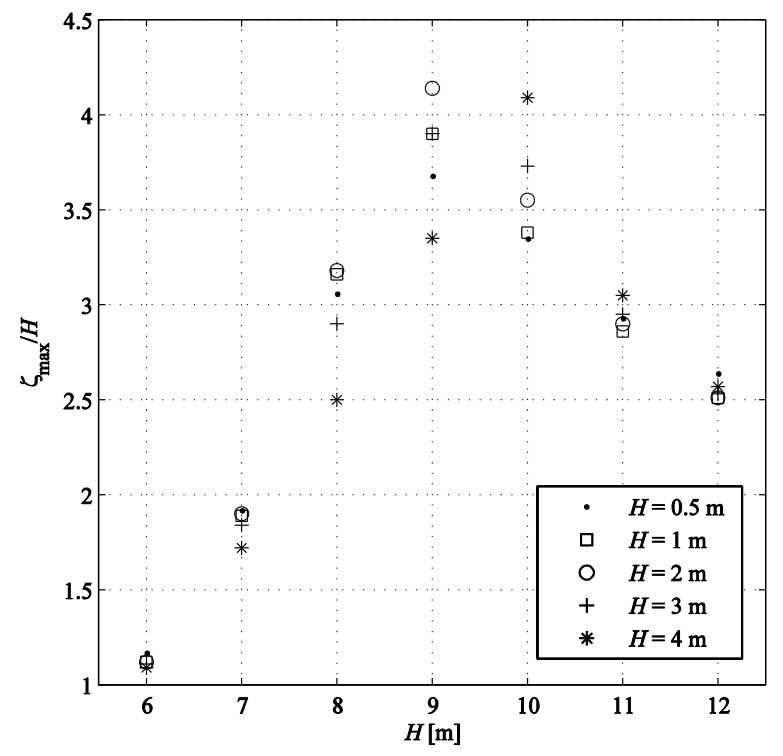

Figure 5. The motion response amplitude of the CECO moving part for different regular wave conditions.

\subsection{Wave energy capture efficiency}

The performance of CECO was also analyzed under irregular waves (test conditions resulting from combining: $H_{s}=0.5,1.0,2.0,3.0$ and $4.0 \mathrm{~m}$ with $T_{p}=6,7, \ldots, 12 \mathrm{~s}$ ). To examine the efficiency of the device, the power captured was calculated for each test case (Eq. 5) and, then, the corresponding values of the capture width $\left(C_{W}\right)$ and of the relative capture width $\left(C_{N}\right)$, using Eq. 9 and Eq. 11, respectively.

Although the results show that the efficiency of the tested device strongly depends on the sea state characteristics, CECO captures between 20 and $40 \%$ of the incident wave energy, for all the wave conditions (Fig. 6). The maximum values of capture width were obtained for peak period between $T_{p}=$ 8 and $10 \mathrm{~s}$, and the lowest values of the significant wave height. In fact, the maximum efficiency is reached in the test case with $H_{s}=1 \mathrm{~m}$ and $T_{p}=8$. Bearing in mind these results, the optimal operation conditions of the tested model can be set in the following range of wave parameters: $H_{s} \in[0.5 ; 3] \mathrm{m}$ and $T_{p} \in[8 ; 10] \mathrm{s}-$ for which $C_{N}$ stays above $30 \%$.

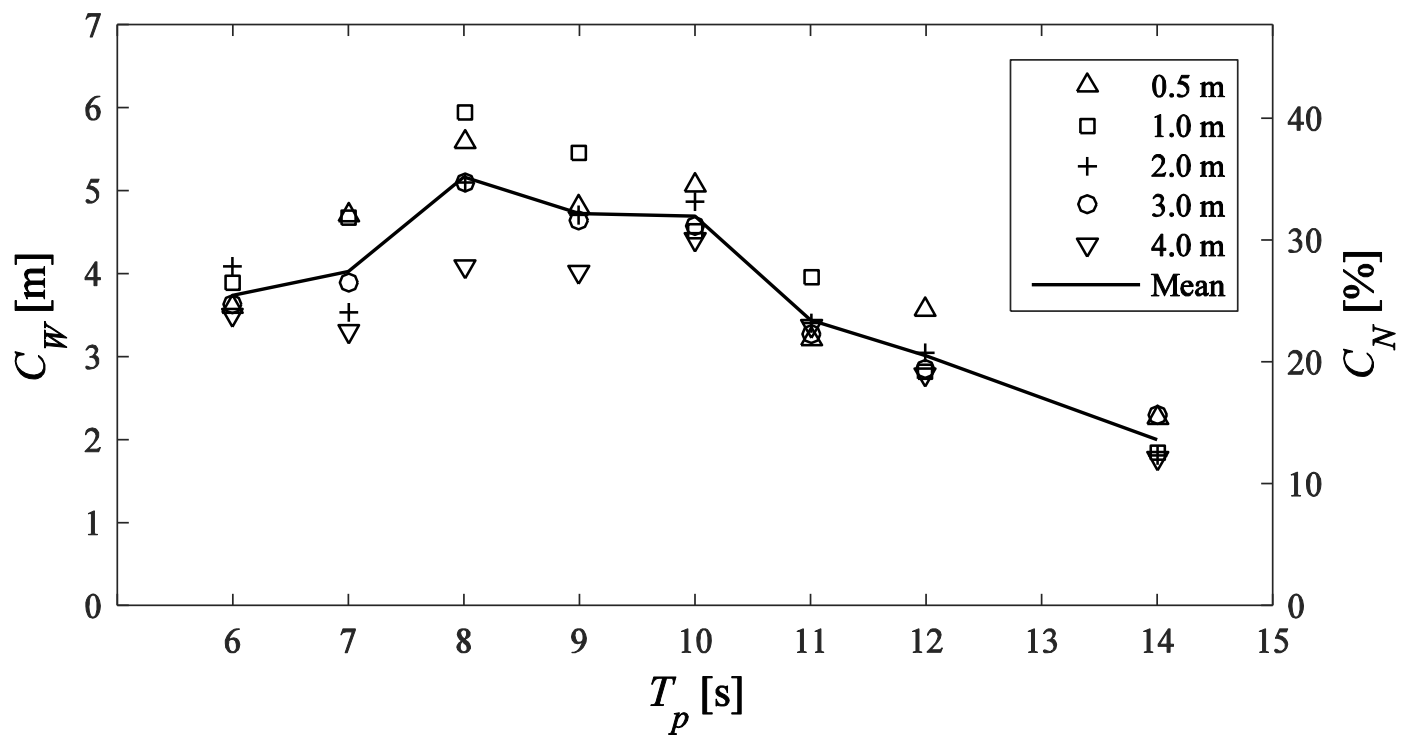

Figure 6. Capture width of CECO for different irregular wave conditions. 


\section{CONCLUSIONS}

In this work, numerical modelling was used to investigate the performance of CECO, a promising WEC based on the floating bodies' principle of operation. A CECO unit in a 1:20 geometrical scale was simulated in the time domain under regular and irregular wave conditions. A two-stage approach was used, in which the BEM is applied to obtain the frequency-dependent hydrodynamic coefficients.

The force that drives the PTO was modelled considering two terms: a constant force and a damping force, which were calibrated with results from previous physical model tests. Bearing in mind the good agreement between the numerical simulations and the physical model results, the numerical approach followed was considered satisfactory to reproduce the behavior of CECO.

The motion amplitude of CECO floating part was amplified with respect to the amplitude of the incident waves for most of the regular wave conditions tested. The efficiency of the device is very high, being CECO able to capture up to $40 \%$ of the available wave power.

The wave parameters and, particularly, the wave period, influence the behavior and the efficiency of this WEC. The ideal range of operation corresponds to sea states with significant wave heights between 0.5 and $3 \mathrm{~m}$ and peak wave periods between 8 and $10 \mathrm{~s}$, for which the relative capture width is always above $30 \%$.

In sum, this work presents a valid numerical modelling approach for simulating the behavior of CECO. Further research is required to optimize and develop this promising concept. Relevant aspects to be covered include the design and implementation of the control strategies for the PTO as well as the optimization of the shape and geometry of CECO floating elements.

\section{ACKNOWLEDGMENTS}

The authors wish to acknowledge FCT (Fundação para a Ciência e a Tecnologia) for supporting the project PTDC/MAR-TEC/6984/2014. M. López also wishes to acknowledge FCT for the postdoctoral grant SFRH/BPD/102112/2014. The CECO concept has been idealized by José Pinho Ribeiro (Patent N. PT 105015).

\section{REFERENCES}

Ansys. 2016. ANSYS AQWA. 17 ed. ANSYS, Ltd., Canonsburg, PA, USA.

Bosma, B., Sheng, W., and F. Thiebaut. 2014. Performance Assessment of a Floating Power System for the Galway Bay Wave Energy Test Site, Proceedings of the International Conference on Ocean Energy (ICOE), 6 November 2014, Halifax, USA.

Carballo, R., Sánchez, M., Ramos, V., Fraguela, J., and G. Iglesias. 2015. Intra-annual wave resource characterization for energy exploitation: A new decision-aid tool, Energy Conversion and Management; 93, 1-8.

Cummins, W. 1962, The impulse response function and ship motions. The David Taylor Model Basin (DTMB), Washington DC, USA.

Day, A. H., Babarit, A., Fontaine, A., He, Y. P., Kraskowski, M., Murai, M., ... and H.K. Shin. 2015. Hydrodynamic modelling of marine renewable energy devices: A state of the art review, Ocean Engineering, 108, 46-69.

Delauré, Y. M. C., and A. Lewis. 2003. 3D hydrodynamic modelling of fixed oscillating water column wave power plant by a boundary element method. Ocean engineering, 30(3), 309-330.

López, M., Taveira-Pinto, F., and P. Rosa-Santos. 2016. Influence of the power take-off characteristics on the performance of CECO wave energy converter. Energy, 120, 686-697.

López M., Veigas, M., and G. Iglesias. 2015. On the wave energy resource of Peru, Energy Conversion and Management, 90, 34-40.

López, I., Pereiras, B., Castro, F., and G. Iglesias. 2014. Optimisation of turbine-induced damping for an OWC wave energy converter using a RANS-VOF numerical model, Applied Energy; 127, 10514.

Muliawan, M.J., Karimirad, M., Gao, Z., and T. Moan. 2013. Extreme responses of a combined spartype floating wind turbine and floating wave energy converter (STC) system with survival modes, Ocean Engineering, 65, 71-82.

Payne, G. S., Taylor, J. R., Bruce, T., and P. Parkin. 2008. Assessment of boundary-element method for modelling a free-floating sloped wave energy device. Part 1: Numerical modelling, Ocean Engineering, 35(3), 333-341.

Rhinefrank, K., Schacher, A., Prudell, J., Hammagren, E., Zhang, Z., Stillinger, C., ... and S. Yim. 2011. Development of a Novel 1: 7 Scale Wave Energy Converter, Proceedings of ASME 2011 30th International Conference on Ocean, Offshore and Arctic Engineering, ASME, 935-944. 
Rosa-Santos, P., Taveira-Pinto, F., Teixeira, L., and J. Ribeiro. 2015. CECO wave energy converter: Experimental proof of concept. Journal of Renewable and Sustainable Energy; 7:061704.

Ruehl, K., and D. Bull. 2012. Wave energy development roadmap: design to commercialization, Oceans, IEE, 1-10.

Taveira-Pinto, F., Iglesias, G., Rosa-Santos, P., and Z.D. Deng. 2015. Preface to Special Topic: Marine Renewable Energy, Journal of Renewable and Sustainable Energy, 7:061601.

Veigas, M., Lopez, M., Romillo, P., Carballo, R., Castro, A., and G. Iglesias. 2015. A proposed wave farm on the Galician coast, Energy Conversion and Management, 99, 102-11.

Veigas, M., López, M., and G. Iglesias. 2014. Assessing the optimal location for a shoreline wave energy converter, Applied Energy, 132, 404-411.

Zhang, Y., Zou, Q. P., and D. Greaves. 2012. Air-water two-phase flow modelling of hydrodynamic performance of an oscillating water column device, Renewable Energy, 41, 159-170. 